\title{
Protocolo de Atención Odontológica Integral para niños hasta los 5 años de edad
}

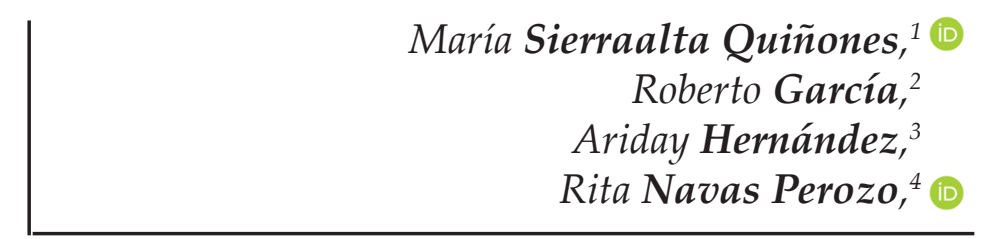

\section{Resumen}

La atención odontológica del niño de corta edad en Latinoamérica se iniciaron en Brasil en el año 1983 a través de la implementación del programa "Plan de Atención Odontológica para el Primer Año de Vida", cuya praxis está basada en la filosofía de tratamiento odontológico educativo, preventivo y curativo para niños el primer año de vida con amplio acompañamiento longitudinal; liderado por el Dr. Luiz Reinaldo de Figueiredo Walter y colaboradores adscritos a la disciplina de Odontopediatría y Ortodoncia de la Universidad Estadual de Londrina. Objetivo: Diseñar un protocolo de atención odontológica integral para niños hasta los 5 años de edad y sus padres o cuidadores. Metodología: Investigación proyectiva, no experimental con diseño transversal y de fuentes documentales provenientes de la literatura científica queestableciólos mejores niveles de evidencia posible para sustentar la formulación del protocolo. Resultados: el protocolo se estructuro en 4 fases: I Fase Inicial (atención a la gestante, madre y niño), II Fase Diagnóstica (atención del niño), III Fase Preventiva, IV Fase Curativa del niño. Conclusión: Existe suficiente evidencia científica disponible para aseverar que la atención odontológica de niños menores de 5 años es fundamental para garantizar una población adulta futura con adecuada salud bucal. La puesta en práctica del protocolo propuesto contribuirá a controlar los procesos de enfermedades bucales como la CPI-Severa, maloclusión, periodontitis y sus factores de riesgo comunes con las enfermedades no trasmisibles.

Palabras clave: BIREME (DeCS) Protocolo, atención odontológica integral, niños.

\footnotetext{
${ }^{1}$ Magister Scientiarum en Odontopediatría. Doctorante del Programa de Doctorado/PhD en Ciencias odontológicas. Docente del Postgrado de Odontopediatria y Escuela de la Facultad de Odontología. Facultad de Odontología. Universidad del Zulia. Maracaibo- Venezuela.

Doctor en Ciencias odontológicas. Especialista en Odontopediatría. Docente del programa de Postgrado de Odontopediatria. Director de la División de estudios para Graduados. Facultad de Odontología. Universidad del Zulia. Maracaibo- Venezuela.

Médico Cirujano, Especialista Puericultura y Pediatría.

${ }^{4}$ Magister Scientiarum en Administración del Sector Salud. Mención Planificación. Área Epidemiologia y Práctica Odontológica. Instituto de Investigaciones. Facultad de Odontología. Universidad del Zulia. Maracaibo, Venezuela.
} 
Artigo original

\section{Protocolo de atendimento odontológico integral para crianças de até 5 anos de idade}

\section{Resumo}

$\mathrm{O}$ atendimento odontológico de crianças pequenas na América Latina teve início no Brasil em 1983 com a implantação do programa "Plano de Assistência Odontológica para o Primeiro Ano de Vida", cuja prática se baseia na filosofia do tratamento odontológico educacional, preventivo e curativo para crianças no primeiro ano de vida com acompanhamento longitudinal extenso; liderado pelo Dr. Luiz Reinaldo de Figueiredo Walter e colaboradores lotados na disciplina de Odontopediatria e Ortodontia da Universidade Estadual de Londrina. Objetivo: Elaborar um protocolo de atendimento odontológico integral para crianças de até 5 anos de idade e seus pais ou responsáveis. Metodologia: Pesquisa projetiva, não experimental, com delineamento transversal e fontes documentais da literatura científica que estabeleceram os melhores níveis de evidência possíveis para subsidiar a formulação do protocolo. Resultados: o protocolo foi estruturado em 4 fases: I Fase Inicial (cuidado da gestante, mãe e filho), II Fase Diagnóstica (cuidado da criança), III Fase Preventiva, IV Fase Curativa da criança. Conclusão: Existem evidências científicas suficientes para afirmar que o atendimento odontológico de menores de 5 anos é fundamental para garantir uma futura população adulta com saúde bucal adequada. A implantação do protocolo proposto contribuirá para o controle dos processos de doenças bucais, como ICC grave, maloclusão, periodontite e seus fatores de risco comuns às doenças não transmissíveis.

Palavra-chave: Protocolo BIREME (DeCS), atendimento odontológico abrangente, crianças.

Original article

\section{Comprehensive Dental Care Protocol for Children up to 5 years of age}

\begin{abstract}
The dental care of young children in Latin America began in Brazil in 1983 through the implementation of the program "Dental Care Plan for the First Year of Life", whose practice is based on the philosophy of dental treatment educational, preventive and curative
\end{abstract}

for children in the first year of life with extensive longitudinal monitoring; led by Dr. Luiz Reinaldo de Figueiredo Walter and collaborators assigned to the discipline of Pediatric Dentistry and Orthodontics of the State University of Londrina. Objective: Design a comprehensive dental care protocol for children up to 5 years of age and their 
parents or caregivers. Methodology: Projective, non-experimental research with a cross-sectional design and documentary sources from the scientific literature that established the best possible levels of evidence to support the formulation of the protocol. Results: the protocol was structured in 4 phases: I Initial Phase (care of the pregnant woman, mother and child), II Diagnostic Phase (care of the child), III Preventive Phase, IV Curative Phase of the child. Conclusion: There is sufficient scientific

\section{Introducción}

De acuerdo a la información registrada en la literatura, la atención odontológica del niño de corta edad se remonta al siglo XX; sin embargo, durante su devenir histórico ésta ha transitado por diferentes situaciones. Es a partir de la década de 1980 que a nivel de Latinoamérica específicamente en Brasil, los conocimientos son sistematizados y adaptados en sistemas odontológicos públicos y privados brasileños; gracias a la iniciativa de un grupo de profesores liderados por el Dr. Luiz Reinaldo de Figueiredo Walter adscritos a la disciplina de Odontopediatría y Ortodoncia de la Universidad Estadual de Londrina (UEL); con el proyecto "Plan de Atención Odontológica para el Primer Año de Vida", cuya praxis está basada en la filosofía de tratamiento odontológico educativo, preventivo y curativo para niños el primer año de vida con amplio acompañamiento longitudinal; permitiendo transformar del marco conceptual de la odontología: el paradigma de que sólo se debe preocupar evidence available to assert that dental care for children under 5 years of age is essential to guarantee a future adult population with adequate oral health. The implementation of the proposed protocol will contribute to control the processes of oral diseases such as severe ICC, malocclusion, periodontitis and their common risk factors with noncommunicable diseases.

Keywords: MeSH: $\quad$ Protocol, comprehensive dental care, children.

por la salud bucal de su hijo "a partir de los dos o tres años" a: "desde el nacimiento". 1

En relación a las condiciones bucales de la población en edad preescolar a nivel latinoamericano los perfiles epidemiológicos bucales reflejan una elevada prevalencia de caries dental, traumas dento alveolares, maloclusión dental.

En relación a la caries dental, la cumbre global de caries de primera infancia (CPI) efectuada en Bangkok en 20182 define a esta como la presencia de una o más superficie (cavitadas o no cavitadas) perdida u obturada debido a caries, en cualquier diente primario de un niño menor de 6 años de edad utilizando el sistema internacional de detección y diagnóstico de caries, consensuado en Baltimore, Maryland. USA en el año 2005, para la práctica clínica, la investigación y el desarrollo de programas de salud pública. El objetivo fue desarrollar un método visual para la detección de la caries, en 
fase tan temprana como fuera posible, y que además detectara la gravedad y el nivel de actividad de la misma.

En Venezuela Peña y Zavarce ${ }^{3}$ establecieron la prevalencia de caries dental utilizando el sistema ICDAS (International Caries Detection and Assessment System) en pacientes entre 6 meses y 6 años de que acudieron a consulta pediátrica en la Ciudad de Valencia, Estado Carabobo, encontrando que el $66,7 \%$ de los niños presentaron caries dental.

Por otra parte también se ha estudiado el impacto de la calidad de vida relacionada con salud bucal (CVRSB) y la caries dental en niños de 0 a 6 años de edad. Estos estudios han demostrado que la CPI y la CPI-S generan un impacto negativo en la calidad de vida relacionada a salud bucal en los niños y en sus familias. ${ }^{4-5}$

La presencia de caries en niños está relacionada con una serie de factores biológicos, sociales y comportamentales; ${ }^{6-9}$ también pueden producirse alteraciones del desarrollo infantil temprano (lenguaje, psicomotor, cognitivo, social y emocional), ${ }^{10}$ problemas estéticos, ${ }^{11}$ dificultades para la alimentación, ${ }^{12-14}$ aparición de maloclusiones y hábitos orales $^{15-18}$ consumo azúcar, ${ }^{19}$ además de repercusiones médicas-odontologicas, ${ }^{20}$ financieras, ${ }^{21,22}$ baja escolaridad de los padres, ${ }^{23}$ bajo nivel socioeconómico, ${ }^{24,25}$ hábitos alimentarios ${ }^{26,27}$ e higiénicos inadecuados ${ }^{28}$ entre otros.

Para disminuir algunos de estos factores de riesgos a la CPI, se hace necesario instrumentar modelos o protocolos de atención integral de salud bucal en el que se aborde no solo al infante, desde el proceso salud-enfermedad, sino a sus madres, padres, familiares o cuidadores mediante estrategias de promoción, prevención y educación en salud bucal.

La Declaración de Shanghai en 2016 sobre Promoción de la Salud, de la OMS ${ }^{29}$ sostiene que para que la población sea proactiva en el cuidado de su vida y de su salud, debe ser sujeto de acciones dirigidas hacia la modificación de actitudes, comportamientos y estilos de vida, en un ambiente que le permita el máximo desarrollo personal y social, y que además deben elaborarse estrategias para que las personas tengan conocimientos sobre salud, se fomente la capacidad de los ciudadanos para controlar su salud y los determinantes que la condicionan, y para sean más conscientes sobre cómo llevar una vida sana.

Estos planteamientos se corresponden con la teoría cognitiva social que centra su atención en la capacidad de las personas para hacer cambios en sus comportamientos, aborda el aprendizaje de las personas, el cual ocurrirá al observar a otros dentro del contexto de interacciones sociales, experiencias e influencias externas de los medios. Respecto a la salud bucal esta teoría se ha aplicado principalmente en las intervenciones conductuales para reducir la caries dental en niños y adultos, al centrar la atención en la capacidad de las personas para hacer cambios en sus comportamientos respecto a higiene oral, consumo de carbohidratos y azucares, y creencias de los padres sobre el cepillado dental entre otros. ${ }^{30}$

Con el fin último de prestar a los usuarios una atención de calidad, existen a disposición de los profesionales diferentes herramientas que contribuyen 
a tomar decisiones en momentos de incertidumbre. Los protocolos, guías clínicas, procedimientos, manuales y otros, son documentos que además de contribuir a normalizar la práctica, son una fuente poderosa de información y al mismo tiempo, facilitan la atención al personal de nueva incorporación. ${ }^{31}$

En el diseño de los protocolos de atención integral de salud bucal al niño y sus padres, debe concretarse y comprometerse la participación de otros profesionales que aporten sus conocimientos y esfuerzos para promover la salud general y bucal a fin de alcanzar una adecuada salud bucal en el adulto.

Esta investigación se planteó como objetivo la elaboración de un protocolo de atención odontológica integral para niños hasta los 5 años de edad.

\section{Metodología}

Investigación de tipo proyectiva con diseño documental proveniente de la literatura científica la cual fue revisada para establecer los mejores niveles de evidencia posible para la elaboración de un protocolo de atención odontológica integral de niños hasta los 5 años de edad.

Para la revisión de la literatura científica se construyó un instrumento donde se registró la información proveniente de los artículos científicos seleccionados, relacionados con los factores de riesgo a caries dental en niños menores de 05 años de edad, atención odontológica a la gestante y otros con la finalidad de determinar los mejores niveles de evidencia posible sobre dichos factores. Se utilizaron para ello buscadores científicos tales como Pubmed/medline, Redalyc.org, SciELO.org y Elsevier, para la selección y análisis de la información científica disponible en los últimos cinco años.

Con la determinación de los mejores niveles de evidencia posible, se procedió a la elaboración del protocolo de atención odontológica integral en niños menores de 05 años de edad y sus padres. Se siguió la estructura establecida por Sánchez y $\operatorname{col}^{31}$ y Kredo y col. ${ }^{32}$

\section{Aspectos éticos de la Investigación}

Este estudio se clasificó como investigación sin riesgo ya que no requirió consentimiento informado por cuanto no hubo ningún tipo de intervención clínica con personas humanas.

\section{Resultados}

En salud un protocolo, tiene el significado de reglas o instrucciones sobre cómo hacer un proceso en particular de manera explícita y sin errores, es un documento dirigido a facilitar el trabajo clínico que incluye un conjunto de actividades y procedimientos relacionados con un determinado proceso asistencial y tiene como propósitos normalizar la práctica, disminuir la variabilidad en la atención y los cuidados de los pacientes, mejorar la calidad de los servicios prestados y facilitar la atención a personal de nueva incorporación. ${ }^{32}$

Objetivos del protocolo Atención odontológica integral para niños hasta los 5 años de edad

1. Guiar y orientar a los odontólogos y Odontopediatras, en el abordaje 
del niño menor de 5 años para el tratamiento preventivo y curativo del sistema estomatognático.

2. Brindar atención odontológica integral al niño desde su nacimiento hasta los 5 años de edad.

3. Proporcionar a los profesionales involucrados un protocolo soportado en la evidencia científica disponible.

4. Constituirse en una guía de atención integral para los padres, cuidadores o responsables del niño.

\section{Destinatarios}

Odontopediátras y otros profesionales de la salud implicados en la atención de los niños, madres, padres y cuidadores.

\section{Población Objeto}

- Pacientes de la primera infancia que asistan a la consulta de Odontopediatría hasta los 5 años en el Sistema de Salud Madre Rafols, Fundación cambiando vidas de Maracaibo - Estado Zulia

- Madres, padres y cuidadores de los niños.

Criterios de exclusión de aplicación de este protocolo

- Paciente/ niños que presenten algún tipo de síndrome o malformaciones craneofaciales.

Profesionales implicados

Odontólogo, Odontopediátras y
Ortopedista: profesional de la salud que se encarga de la asistencia preventiva y curativa del sistema estomatognático del niño y su familia.

Gineco-obstetra, pediatra, neonatólogo y sub-especialistas: profesional de la salud que se encarga de la asistencia general del niño desde su nacimiento.

Trabajador social: profesional encargado de la valoración y abordaje de la familia y la comunidad, indaga la situación socioeconómica, cultural y cambios cognitivos en las creencias personales y conductuales presentes en los grupos familiares. Conforma equipos multiplicadores y facilitadores en el proceso de educación y concientización de las comunidades hacia la promoción de vidas saludables.

Nutricionista: personal de la salud que evalúa los alimentación consumidos en la etapa de crecimiento del niño, adulto y grupo familiar.

Consejeros Comunales, Maestros y Profesores: personas que están en contacto con la comunidad e intervienen favorablemente en la motivación, el proceso de aprendizaje de su higiene personal. Visita a los escenarios donde se están ejecutados las actividades educativas para determinar el funcionamiento de la misma.

Recursos institucionales y materiales

Área clínica, camilla para recién nacidos, macril, sillón odontológico, insumos, instrumental y equipos odontológicos. 
Desarrollo del protocolo.

Antes de iniciar las evaluaciones odontológicas, el operador debe cumplir las normas de bioseguridad y obtener el consentimiento informado de los padres, madres, o cuidadores de los niños de acuerdo a la norma Normas Helsinski 2013. ${ }^{33}$

El protocolo de atención integral odontológica preventivo curativo, inicia incorporando a la madre a la consulta odontológica. La atención del neonato debe estar dentro de los primeros días de vida, comenzando desde el control de niño sano con el fin de garantizar la buena salud bucal a lo largo de su desarrollo. La madre y el niño deben integrarse a todo un conjunto de interconsultas (pediatría, nutrición, trabajo social, entre otros) donde la inter-referencia es obligatoria.

A continuación se esquematizan los pasos a seguir para la atención odontológica del niño, enfatizando la responsabilidad de la asistencia del mismo a sus padres o cuidadores, garantizando de esta manera el acceso a la atención, protección y rehabilitación de su salud bucal.

\section{FASES}

Es importante destacar que los diferentes centros de interés de este protocolo abarcan: recién nacido sano o patológico (0-28 días de nacido), lactante menor (29 días de nacido a los 12 meses de edad), lactante mayor (13 a 24 meses de edad), preescolar (25 a 71 meses de edad)

\section{FASE INICIAL (ATENCIÓN A LA GESTANTE, MADRE, NIÑO) Figura 1}

1. El gineco-obstetra tratante deberá referir a la gestante desde que inicia su control prenatal a la consulta odontológica para ser evaluada y rehabilitada, si fuese ese el caso, debido a la importancia de mantener la cavidad bucal libre de focos de infección ${ }^{7-9}$

\section{FASE INICIAL (ATENCIÓN A LA GESTANTE, MADRE, NIÑO)}

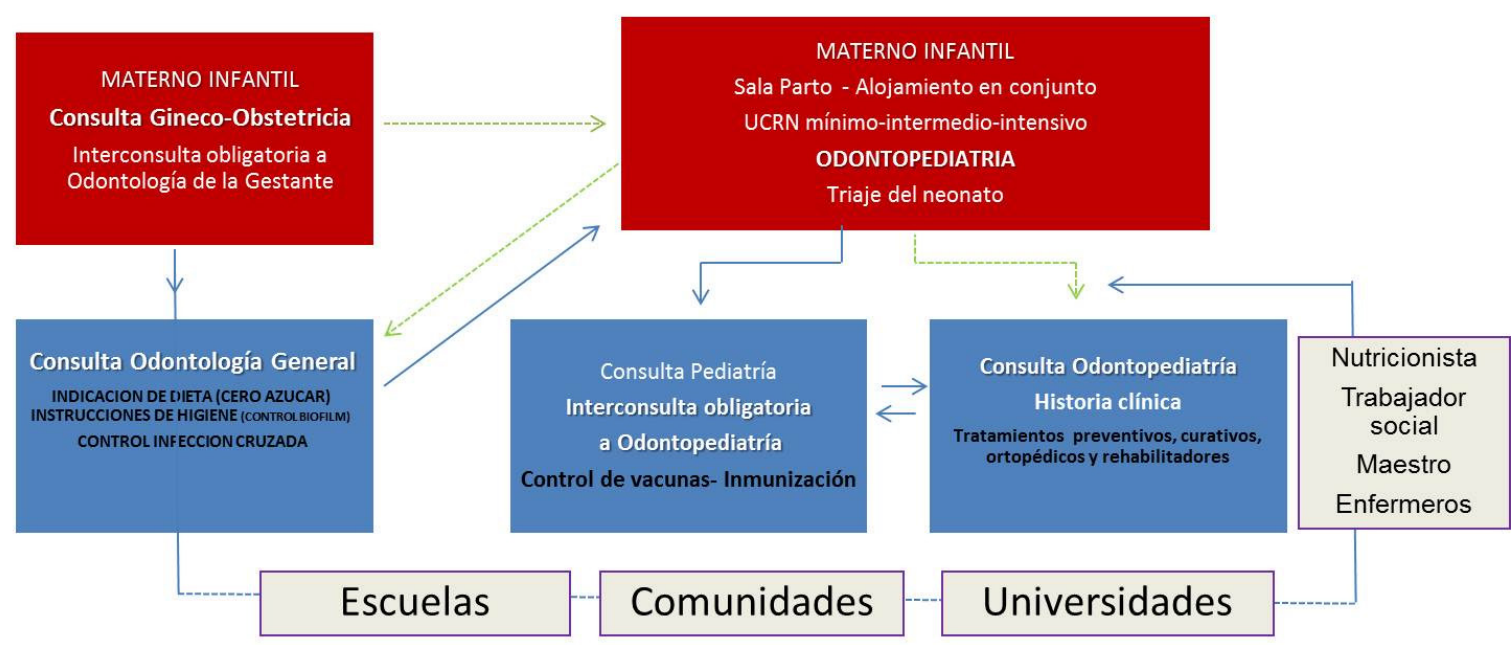

Figura 1. Fase inicial (atención a la gestante, madre, niño) 
2. Se dictaran ciclos de charlas educativas basadas en la promoción y prevención de la salud estomatognática. Estas serán continuas en la consulta externa, hospitalización y en el alojamiento en conjunto (madre-hijo) para conocer la importancia de asistir al odontólogo durante la gestación y en el nacimiento del bebé, identificando los factores de riesgo en las madres (hormonales, vasculares, salivales, microbiológicos e inmunológicos) que pueden incidir en la salud bucodental de las gestantes y el feto, reconociendo la periodontitis como principal factor de riesgo para parto pretérmino, preeclampsia, diabetes gestacional. ${ }^{12,34,35}$ Se realizaran demostraciones continuas sobre el control del biofilm, ingesta de alimentos azucarados, dieta cariogénica, disminución en la frecuencia de la higiene para eliminar las creencias populares que limitan el acceso a la atención odontológica en la gestante. ${ }^{36,37}$ El tratamiento odontológico del infante brinda la posibilidad de mantener la salud, prevenir la enfermedad y representa una buena práctica de promoción de la salud, de una manera muy simple, eficaz y a bajo costo. El equipo de salud guiado por el Odontopediatra, es el responsable de educar para la salud a la gestante, a los padres, cuidadores y representantes en cuanto a hábitos dietéticos, de higiene bucal, ya que las enfermedades bucales son prevenibles en su gran mayoría controlando los factores de riesgo en el hogar.

3. Inmediatamente después del parto la madre será llevada a una sala conjunta con su bebé sano y si el recién nacido presenta alguna patología es llevado a la unidad de cuidados del recién nacido (mínimo, intermedio o intensivo); cualquiera sea el caso el Odontopediatra deberá realizar el triaje al neonato, motivando a la madre a efectuar la primera visita odontológica del bebé.

4. En su primera consulta con el pediatra, éste debe referir con obligatoriedad al bebé al servicio de odontología de la institución, para recibir su primera consulta odontopediátrica. Las citas sucesivas serán mensuales, debiendo coincidir con los controles de consulta de niño sano o su inmunización. En el cartón de vacunas se registraran la erupción dentaria del niño.

5. La madre deberá ser referida al nutricionista $y$ al trabajador social para la identificación de los factores de riesgo nutricional y sociocultural.

\section{FASE DIAGNOSTICA (ATENCIÓN DEL NIÑO)}

\section{Elaboración de Historia Clínica}

1.1. Anamnesis: Datos personales motivo de consulta, enfermedad actual, antecedentes familiares y antecedentes obstétricos (durante la gestación: alteraciones de tensión arterial, anemia, infecciones urinarias, medicamentos utilizados, consumo de sustancias psicoactivas en el embarazo) y perinatales (№ gesta, semanas de embarazo, tipo de parto, nombre del centro de atención y doctores a cargo, peso y talla al nacer del niño) indagar sobre: hábitos alimenticios en la familia. 


\section{FASE DIAGNOSTICA (ATENCIÓN DEL NIÑO)}

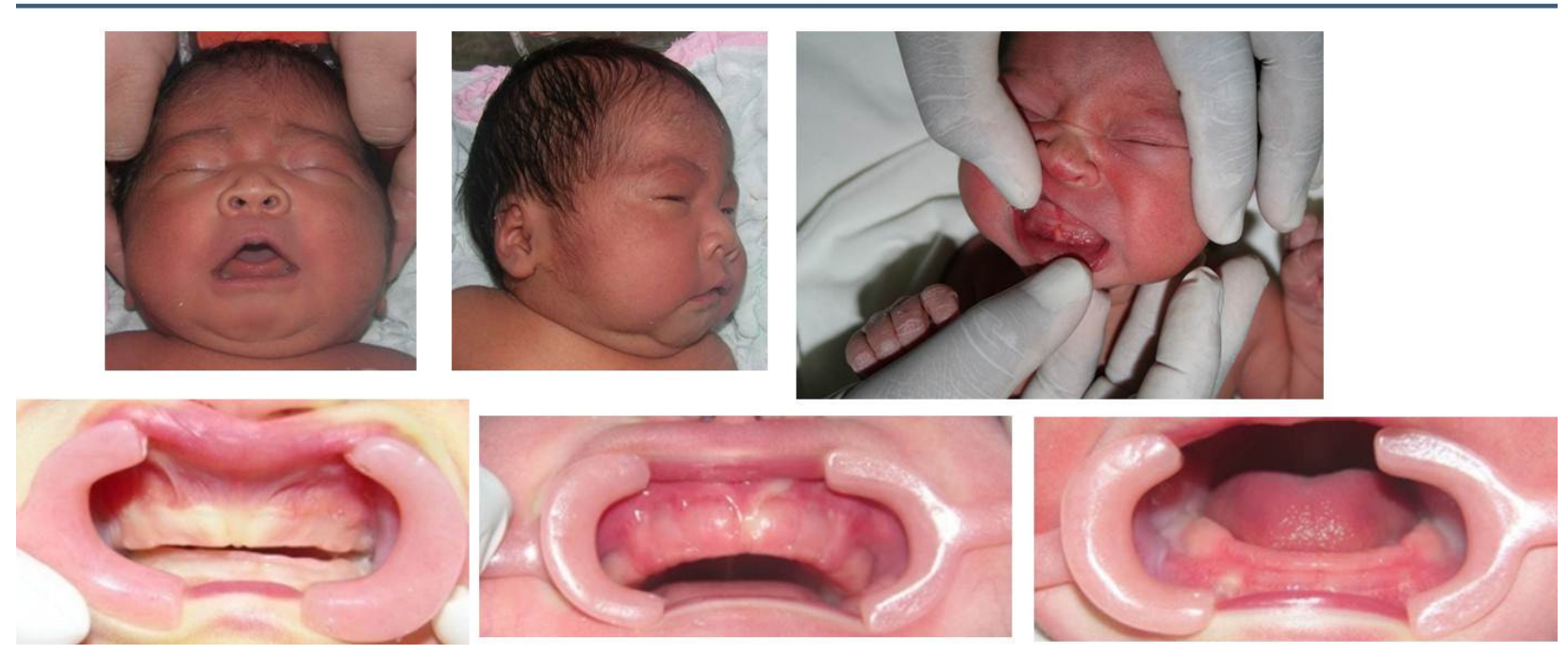

Figura 2. Examen físico.

\subsection{Examen Físico (Figura 2).}

1.2.1 Examen extraoral: La observación del recién nacido sano o patológico debe realizarse en posición de reposo, realizar inspección y palpación de las estructuras craneofaciales y aplicar la biometría craneofacial a través del registro de las medidas craneofaciales con el uso de un Vernier metálico calibrado en milímetros y una cinta métrica; con la finalidad de determinar y evaluar el crecimiento craneofacial en el neonato, se realizaran medidas trimestrales. (Figura 3) Medidas craniométricas: circunferencia $\mathrm{o}$ perímetro cefálico, longitud craneal, diámetro craneal, altura craneal, índice cefálico. Medidas faciales: altura facial superior, altura facial inferior, altura facial total, distancia bicigomática, índice facial, distancia intercantal externa, distancia intercantal interna, longitud nasal, distancia interalar, filtrum nasal, distancia intercomisural, longitud de pabellón auricular derecho e izquierdo, anchura de pabellón auricular derecho e izquierdo, inserción de pabellón auricular, rotación del pabellón auricular. Adicionalmente se debe evaluar la simetría facial, balance facial, perfil facial

1.2.2 Examen Intraoral: Tejidos blandos: labios y duros de cavidad oral.

\subsubsection{Exámenes complementarios, de laboratorio y radiográficos: su indicación va asociada al posible diagnóstico y/o tratamiento.}

\section{Características anatómicas de la cavidad bucal en el Neonato}

En el neonato es importante evaluar, desde el punto de vista anatómico, cada una de las estructuras que la componen; en relación a los labios debemos evaluar tamaño, forma y posición, presencia del apoyo de succión. Con respecto a los rodetes gingivales debemos evaluar el tamaño, forma y posición, presencia del 


\section{FASE DIAGNOSTICA (ATENCIÓN DEL NIÑO)}

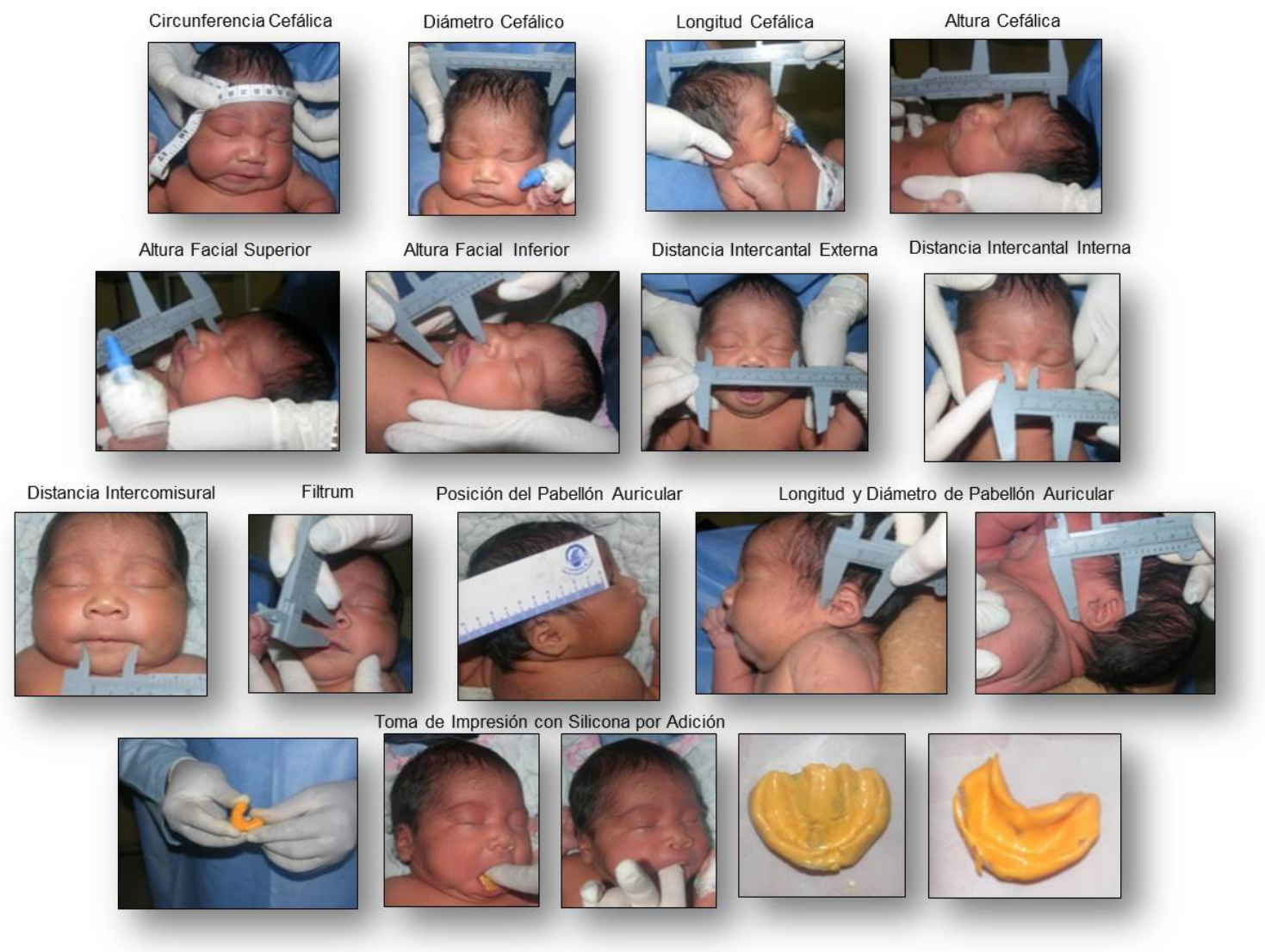

Figura 3. Mediciones antropométricas.

cordón fibroso de Robín y Magitot; a nivel del paladar evaluamos su integridad, forma, presencia de surcos. En cuanto a los tejidos blandos debemos evaluar la presencia o no de frenillo labial superior e inferior y frenillos laterales, tamaño y posición de los mismos y bola de Bichat. En cuanto al piso de boca evaluar su integridad y por último evaluamos la lengua en cuanto a su forma, integridad, posición e inserción. Evaluar la posición de los rodetes en los tres sentidos del espacio (sagital, vertical y transversal).

Ablactación: El niño durante su etapa de crecimiento y desarrollo adquiere nuevas habilidades que se relacionan con el aumento de sus aportes energéticos y requerimientos nutricionales, promoviendo la adecuada maduración del sistema neurológico, cognitivo, digestivo y neuromuscular, logrando la maduración de la deglución, movimientos mandibulares (lateralidad y protrusión), iniciando la masticación, fortalecimiento de la articulación temporomandibular y posteriormente el habla. ${ }^{27}$

La introducción de alimentos cada vez más sólidos progresivamente a partir de los 6 meses con el propósito de complementar la leche materna y asegurar que el lactante pueda conseguir estados de salud óptimos. Es importante entrenar a los padres y cuidadores, sobre el uso correcto de sus manos y la cuchara. Se prohíbe el uso del biberón para la alimentación complementaria. 
Examen de la dentición: Controles odontológicos periódicos, tanto la madre como el niño. Controlando los niveles de microorganismos en la madre, se previene el contagio del niño e identificar los factores de riesgos para CPI a través del método ICDA.

III FASE: FASE PREVENTIVA ${ }^{12,13,2,6}$ Figura 4

La prevención empieza con la intervención durante los periodos prenatal y perinatal, para lograr cambio conductuales en los hábitos alimentarios ehigiénicos, los cuales deben permanecer en el niño durante su primera infancia y ser supervisados por sus padres y cuidadores

Esta fase es la más importante ya que la madre va a promover mediante sus conocimientos sobre salud bucal, la educación del bebé, su familia, la comunidad y el preescolar. Durante el puerperio la mujer se encuentra altamente motivada para mejorar y mantener su propia salud bucal y quieren convertirse en participantes activas en el cuidado preventivo de sus niños. Cada mujer correctamente informada se convierte en "agente divulgador" multiplicando el impacto de la información en la sociedad.

\section{FOMENTO DE LA SALUD BUCAL PARA LA MADRE Y CUIDADORES ${ }^{34-35}$}

Asesoramiento Dietético: en los primeros mil días se inicia la formación del feto por lo que hacemos énfasis en las bases nutricionales, como punto de partida para los cambios de hábitos alimenticios

\section{FASE: FASE PREVENTIVA}

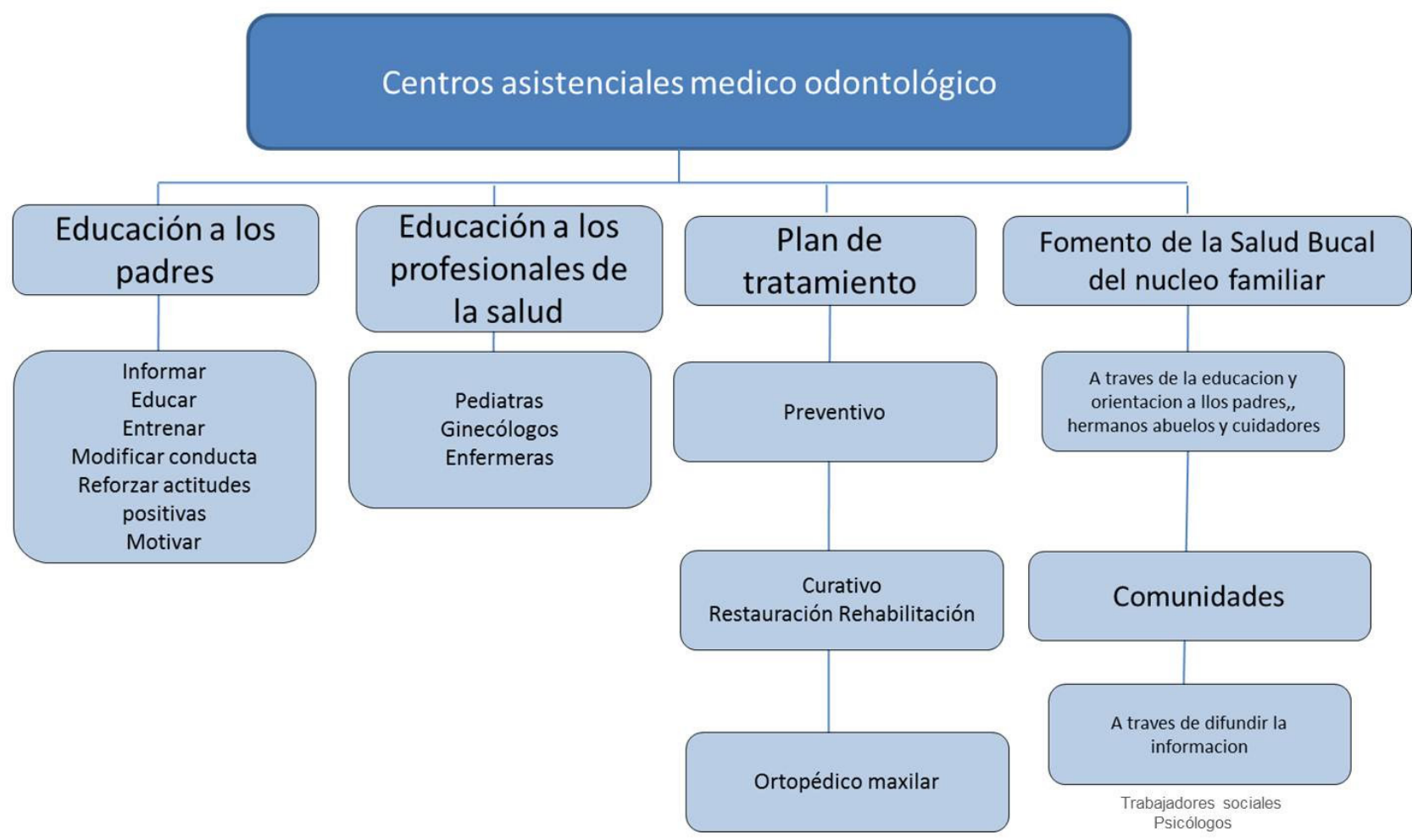

Figura 4. Fomento de la salud bucal para la madre y cuidadores. 
en la madre y familia, ya que es un factor primordial para la salud del individuo a lo largo de su vida. Lo importante es limitar o disminuir la ingesta de carbohidratos refinados y azúcares en las comidas diarias de la familia. Fomentar el uso de alimentos ricos en folato, calcio, fosfato provenientes de proteínas, frutas, verduras y tubérculos con sabores neutros para iniciar la alimentación complementaria a partir de los 6 meses.

Detección de Placa Bacteriana en la madre y cuidadores: $^{38}$ Debe realizarse con un agente colorante como la Fucsina $\mathrm{u}$ otro colorante la detección visualmente del biofilm.

Entrenamiento para la higiene personal: Explicar la técnica de cepillado utilizando macromodelos y luego en vivo con grupos de padres o cuidadores quienes se aplicaran revelado, se observan con un espejo para detectar las fallas del cepillado y corregir la misma. Instruir sobre el uso de hilo dental y enjuague bucal. Estas enseñanzas se deben reforzar y monitorear. Controlar trimestralmente.

Entrenamiento para la higiene de los Rodetes gingivales del lactante: Mediante videos y el uso de muñecos simulamos y entrenamos a las madres y cuidadores la limpieza de la cavidad bucal del bebe a través del masaje de los rodetes gingivales, mucosas, lengua y carillos solo para incorporar este habitó como parte del aseo personal.

\section{Entrenamiento en Lactancia Materna: ${ }^{12,20,34}$} el impacto sobre las estrategias educativas a las futuras madres ${ }^{26}$ ha demostrado su efectividad para prolongar la lactancia materna de forma exclusiva los primeros 6 meses de edad. Realizar simulaciones de las posiciones de la madre en el acto de lactar, mejorar el agarre y la preparación de las mamas para la extracción manual para sus bancos de leche humana. Promover, proteger y apoyar al amamantamiento a través del acompañamiento. Con él bebe evaluar la posición, el agarre, el tiempo de la lactancia. Si se detecta dificultad en la técnica referir a la consulta de Pediatría.

\section{FOMENTO DE LA SALUD BUCAL DEL BEBÉ $12,13,34,35$ :}

\section{Asesoramiento Dietético para el niño}

Indicar lactancia materna de forma exclusiva entendiendo por esta ningún otro alimento líquido o sólido y a libre demanda, durante los primeros 6 meses, por su potencial nutritivo e inmunológico favoreciendo el crecimiento, desarrollo y maduración del sistema estomatognático (succión, respiración, deglución, masticación y fonación) creando competencias labiales, linguales y mandibulares, teniendo la posibilidad menor de adquirir hábitos de succión no nutritiva (succión del dedo, lengua, labio o el uso de chupón)

\section{Entrenamiento para la Higiene bucal del niño: (Figura 5)}

Los hábitos de higiene en los niños deben ir incorporándose desde el nacimiento.

Indicar la higiene de los rodetes con dedal o gasa durante el baño, se realiza masaje en las encías, fondo del vestíbulo, carrillos y lengua, una vez al dia.

Indagar si la alimentación es nocturna (lactancia materna o biberón con fórmula maternizada), en este caso, indicar que debe realizar la higiene después de 


\section{FASE: FASE PREVENTIVA}
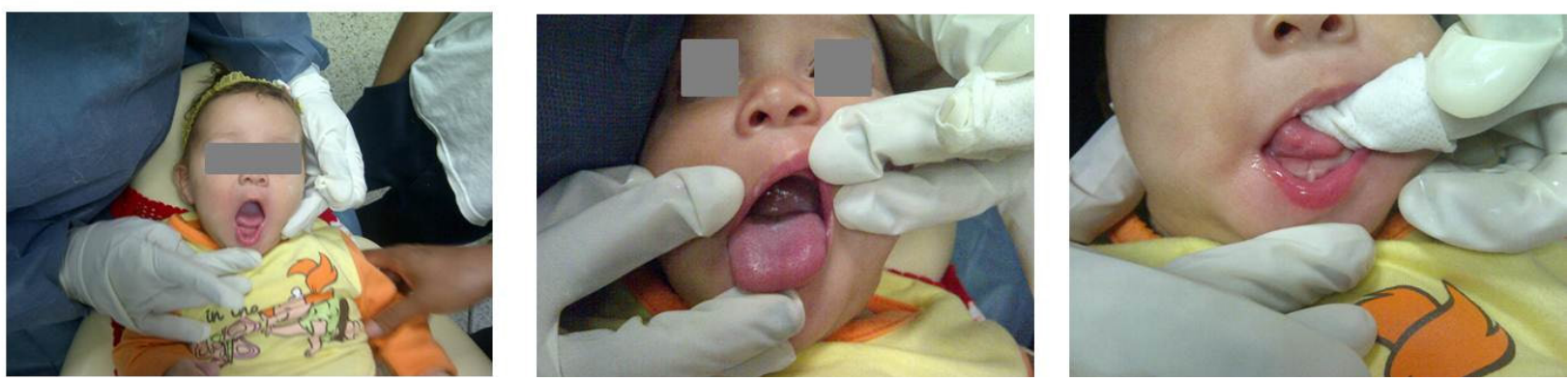

Figura 5. Evaluación clínica

la lactancia, en especial, a partir de la erupción del primer diente en boca.

A partir de la erupción del primer diente, se prescribe la higiene obligatoria, 2 veces al día cepillado dental con dentífricos fluorados de 1000 ppmf a 1400 ppmf, señalando la cantidad de crema de acuerdo a la edad.

El cepillado dental debe estar bajo la supervisión de un adulto, dos veces al día, seleccionando un cepillo de cerdas suaves y de tamaño apropiado para la edad.

Para los niños menores de 3 años de edad se debe usar solo una "mancha" (0,1 mg) o la cantidad equivalente a un grano de arroz (0,1 mg), para los niños de 3 a 6 años de edad se recomienda la cantidad equivalente de una arveja $(0,25 \mathrm{mg})$ y luego de los 6 años se debe usar la técnica transversal $(0,36 \mathrm{mg})$ recomendada por la Academia Americana de Odontología Pediátrica (AAPD, 2014) y la Asociación Dental Americana (ADA, 2014) ${ }^{6}$

\section{Primera Visita del lactante al consultorio Odontopediatrico: ${ }^{34-35}$}

La Consulta debe ser cordial y agradable para motivar a la madre, padres $y$ cuidadores sobre la importante de continuar los cuidados de salud bucal y estomatognática, adecuando el medio bucal para la disminución de los niveles de microorganismos cariogénicos presentes en la cavidad bucal, proporcionando la paralización del proceso carioso. Debe prevalecer la educación en el hogar rigurosa hasta los 24 meses de edad, para controlar la primera ventana de infectividad. ${ }^{39}$ Debe realizarse preferiblemente durante los primeros 28 días de nacido.

En las consultas controles se evaluaran los factores de riesgos en el grupo familiar del niño. Puede indicarse la consulta control mensual, conjuntamente con el control de niño sano del pediatra, cada 3 meses, cada 6 meses o anual dependiendo del caso individual. Detectar y corregir la presencia de hábitos orales perjudiciales.

Al llegar la madre y el niño al consultorio, se evalúa al bebe en el sillón dental, la madre se acostará boca abajo acompañando al recién nacido; otro método a emplear es la posición "rodilla a rodilla", la madre sentada con el Odontopediatra el recién nacido reposa en sus piernas. Revisar la erupción dentaria y desarrollo de la Oclusión. Registrar la secuencia de erupción de dientes primarios, en la historia clínica y en el cartón de vacunas (Figura 6). 


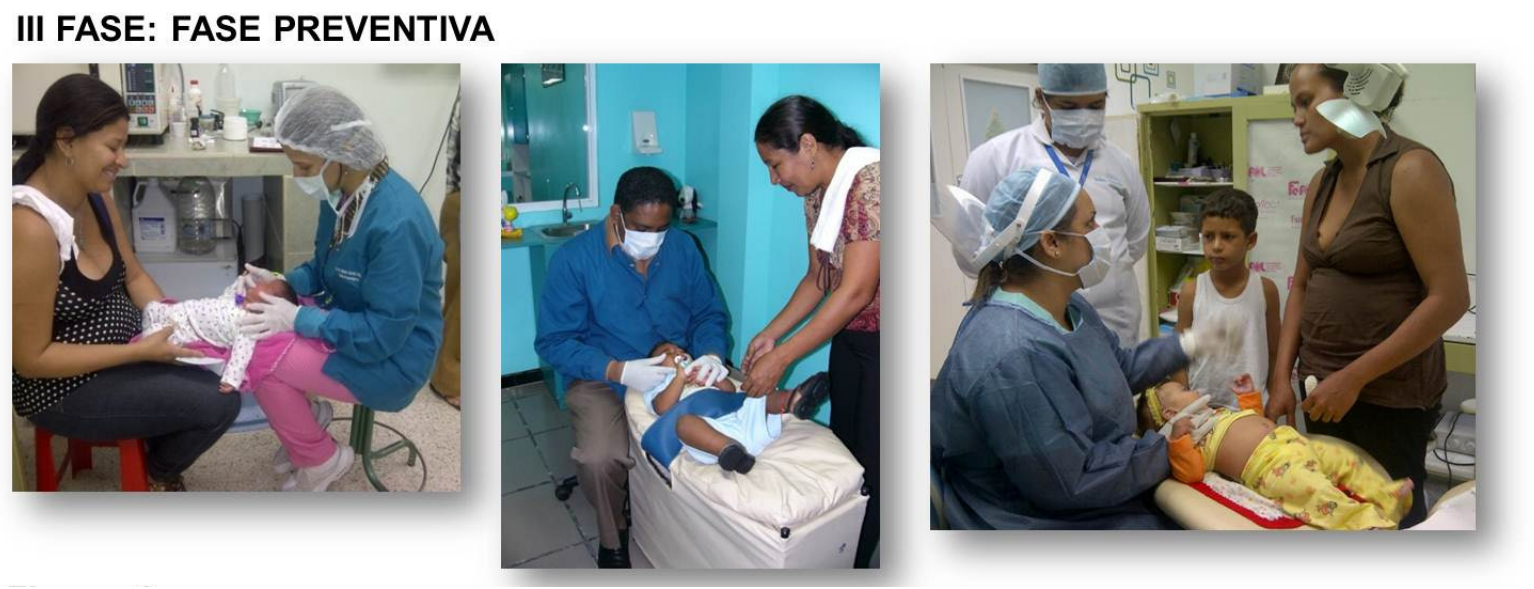

Figura 6. Posiciones de atención odontológica

\section{FASE: FASE CURATIVA}

Evaluar detalladamente los signos clínicos de lesiones de CPI inactivas o activas durante los primeros 2 años de vida, según los patrones estabelecidos por el ICDA. Las lesiones inactivas en esmalte se detectan y controlan en consulta de odontopediatria de forma trimestralmente citando al niño conjuntamente con su proceso de vacunación o consulta con Pediatria, reforzamos normas de higiene en casa para toda la familia.

Aplicar tratamientos preventivos para detener y controlar el avance de la lesión activas iniciales no cavitada con cepillado asistido por su madre o cuidador con dentífrico fluorado diario y nocturno; en el consultorio se aplica barniz fluorado o terapia fluorada realizando seguimiento semestral.

En presencia de lesiones activas referir al nutricionista para verificar la selección y el consumo de alimentos no cariogénicos. Reforzar las indicaciones de higiene, técnica de cepillado con crema dental fluorada después de cada comida y antes de dormir. En presencia de dientes de erupción temprana o dientes supernumerarios: evaluar movilidad, estudio radiográfico y discutir para indicar cirugía (Figura 7).

Al detectar lesiones activa moderada a severa referir al psicopedagogo para aplicar cambios conductuales. Reforzar las indicaciones de higiene, técnica de cepillado con crema dental fluorada después de cada comida, antes de dormir. Se indica el uso de hilo dental y enjuague bucal fluorado (después de los 3 años).

En presencia de lesiones activas moderadas cavitadas en esmalte o dentina se rehabilitará a través del uso de biomateriales odontológicos según planificación clínica del caso (barniz de flúor, fluoraciones tópicas o el uso de sellantes de fosas y fisuras, Tratamiento Restaurador Atraumático empleando ionómeros de vidrio o con resinas infiltrantes). Indicando controles para evaluación trimestral, en lesiones avanzadas selecionar el biomaterial según el estúdio clinico y radiológico para emplear Técnica de Restauración Atraumática o técnica de hall; al involucrar lesiones pulpares se indica tratamiento endodóntico en dientes primarios. 


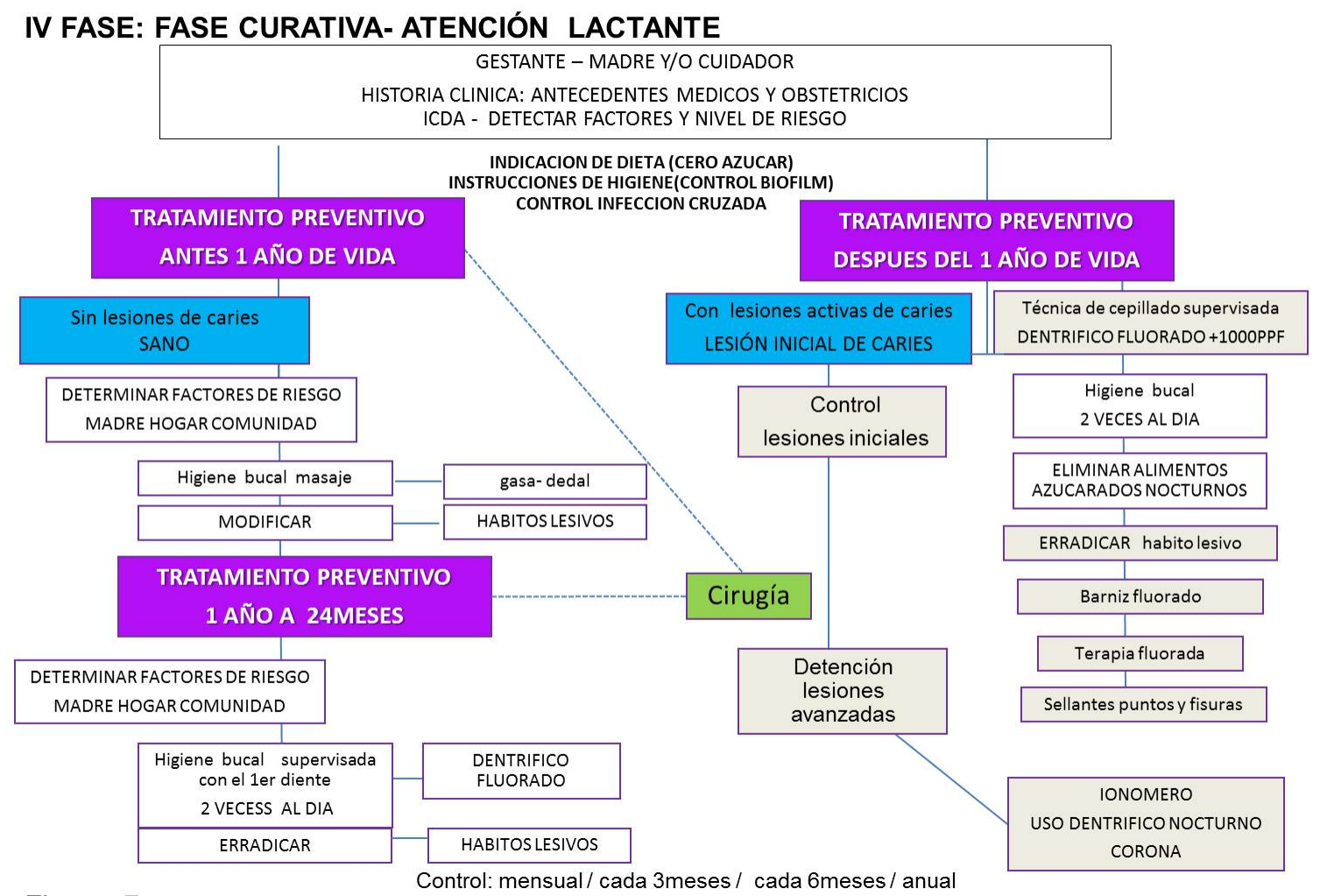

Figura 7. Atención al niño hasta los 2 años.

IV FASE: FASE CURATIVA - ATENCION PREESCOLAR

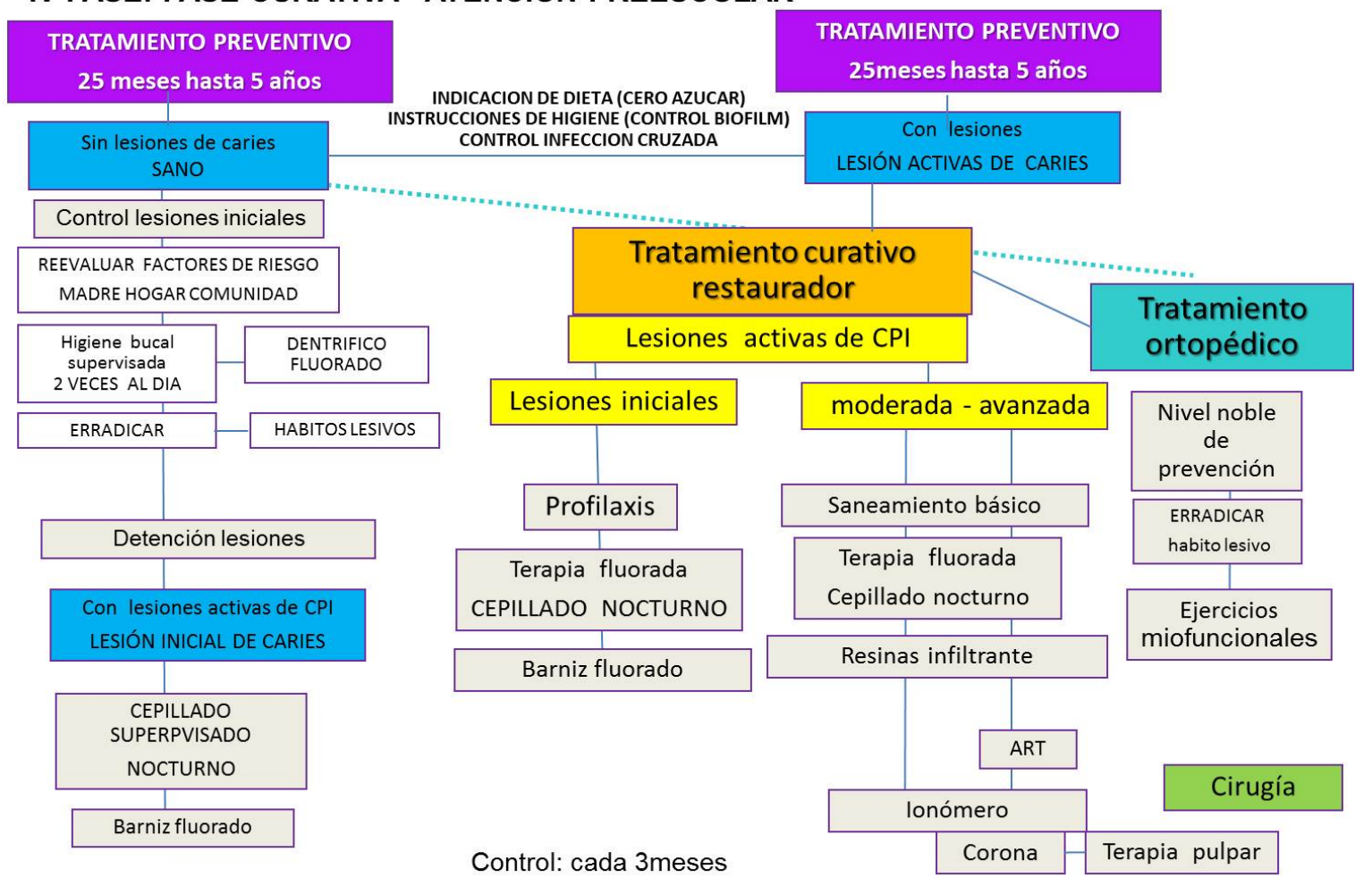

Figura 8. Atención al niño de los 2 años hasta 5 años. 


\section{Discusión}

Después de la revisión de la literatura; se demostró que existe suficiente evidencia científica disponible para aseverar que la atención odontológica de niños menores de 5 años es fundamental para garantizar una población adulta futura con adecuada salud bucal. De allí la necesidad de su atención inmediata desde su nacimiento, e incluso desde su gestación. . $^{1239,40}$

La OMS, la FDI, la IAPD, la ADA, y la AADP2,6,12,13 consideran la CPI como un problema de Salud Pública, por lo que fomentan medidas preventivas sugiriendo que los padres limpien suavemente las encías y los dientes de los bebés al erupcionar el primer diente con dentífrico fluorado. Señalando como factor de riesgo $0^{6,35}$ a la lactancia materna nocturna a libre demanda, después que el primer diente primario comience a erupcionar, ya que se introducen después de los 6 meses otros carbohidratos en la dieta del niño; mientras que la $\mathrm{OMS}^{12}$ en sus directrices del año 2020 asevera que los bebes deben continuar amamantados por dos años o más, y recibir alimentos complementarios nutricionalmente adecuados y seguros para cumplir con sus requisitos nutricionales en evolución.

Esta propuesta de un protocolo de atención odontológica integral para niños menores de 5 años se adhiere a los planteamientos formulados por la OMS, al respecto del amamantamiento hasta los 2 años de edad, siempre que se apliquen las medidas higiénicas y nutricionales al niño bajo supervisión médico-odontológica.

Recomendaciones efectuadas por organismos internacionales como la OMS, ${ }^{12}$ la FDI; ${ }^{13}$ la Declaración de
Bangkok $^{2}$ y la $\mathrm{AAPD}^{6}$ han acordado que se debe realizar la higiene dental 2 veces al día con dentífricos fluorados con 1000ppmf, a partir de la erupción del primer diente; estableciendo que para los niños menores de 3 años de edad se debe usar solo una "mancha" $(0,1 \mathrm{mg})$ o la cantidad equivalente a un grano de arroz $(0,1 \mathrm{mg})$, para los niños de 3 a 6 años de edad se recomienda la cantidad equivalente de una arveja $(0,25 \mathrm{mg})$ y luego de los 6 años se debe usar la técnica transversal $(0,36 \mathrm{mg})$. Esto tratamientos preventivos brindan la posibilidad de fomentar la salud y prevenir la enfermedad, de una forma muy simple, eficaz y de bajo costo. ${ }^{39}$

Todos los organismos anteriormente citados, enfatizan la necesidad de elaborar protocolos, o programas que permitan un abordaje odontológico integral de la gestante y sus niños, con mayor énfasis en los infantes menores de 5 años de edad por cuanto a nivel mundial se reportan altas prevalencias de CPI. ${ }^{12,3,41-44}$

La salud oral de la gestante y la del niño guardan relación entre sí, prioritario como problema de salud pública, que se podría mejorar aplicando el concepto de prevención en fases previas mediante el desarrollo de programas o protocolos de atención a la gestante, al niño, desde su nacimiento y a la madre $y$ cuidadores. . $^{12,13,2,6,34}$

La efectividad de los Programas y Protocolos de Atención Odontológica Materno Infantil buscan contribuir a elevar el nivel de salud mediante la disminución o control de los factores de riesgos sobre todos aquellos que están ligados a componentes conductuales, actitudinales culturales o las políticas públicas de los servicios de salud. 34,39,45 
El Manual de implementación de la OMS como Programa de Salud Oral, Prevención de Enfermedades No Transmisibles, concuerda con la FDI que el manejo de CPI es a través de un equipo de atención primaria siendo actor clave para la prevención y control de la severidad de esta enfermedad. Por otra parte la AAPD plantea que el Odontopediatra es el responsable en el manejo de la madre y el niño.

Este protocolo busca sistematizar la práctica clínica odontológica en la atención de la mujer gestante y su hijo en el Sistema de Salud Madre Rafols bajo la coordinación de la fundación cambiando vidas, para mejorar la calidad de vida de los niños en su primera infancia.

Bandeira y $\mathrm{col}^{46}$ verificaron la percepción favorable de los profesionales acerca de la colaboración interprofesional en el cuidado materno-infantil; sin embargo, en algunos otros programas solo participan los odontólogos.

Moimaz $^{47}$ plantea que el acceso y la calidad de las acciones y servicios de salud están garantizados específicamente en el área de salud bucal materno infantil es necesario ampliar el acceso a mujeres embarazadas y aumentar la resolución de los servicios prestados. Por lo tanto se considera un problema de salud pública sin resolución. . $^{39,47-49}$

Xiao y col. reafirman que el embarazo y la atención prenatal, son los períodos ideales para promover la prevención de la CPI, dado por el comportamiento de la madre en la recepción para la salud oral su niño. $\mathrm{Su}$ investigación ha mostrado resultados efectivos de control del transporte de las bacterias de la madre al niño, restableciendo la salud oral de una futura madre a un estado libre de enfermedad. ${ }^{49}$

Se concluye que después de la revisión de la literatura; se demostró que existe suficiente evidencia científica disponible para aseverar que la atención odontológica de niños menores de 5 años es fundamental para garantizar una población adulta futura con adecuada salud bucal y que la puesta en práctica del protocolo propuesto contribuirá a controlar las enfermedades bucales como CPI-S, maloclusión, la periodontitis y sus factores de riesgo comunes con las Enfermedades No Trasmisibles (ENT) asociadas con consumo excesivo de azúcar, como enfermedades cardiovasculares, diabetes y obesidad. ${ }^{2}$

Este Programa Odontológico Materno Infantil permitirá controlar los riesgos acerca de la relación de lactancia materna y CPI, ofreciendo información a las gestantes y a las puérperas, mediante el $A B C$ en educación y prevención: a) indicaciones de alimentación; lactancia materna exclusiva hasta los 6 meses y alimentación complementaria sin adicionar azúcar hasta los 2 años, $b$ ) instrucciones de higiene para las madres, cuidadores y bebé, c) control de infecciones cruzadas.

\section{Referencias bibliográficas}

1. Figueiredo Walter LR, Ferelle A. Bebé clínica de la Universidade estadual de Londrina: Un resumen Histórico. Rev. Odontopediatr. Latinoam.;3(2). Disponible en: https://revistaodontopediatria.org/index. php/alop/article/view/44.

2. Declaration Early Childhood Caries: IAPD. Int J Pediatric Dent. 2019;29:384-386. Bangkok Declaration. DOI: 10.1111/ipd.12490. Disponible en https://onlinelibrary.wiley.com/doi/full/10.1111/ipd.12490 . 
3. Peña, E. y Zavarce E. Prevalencia de caries dental utilizando el sistema internacional ICDAS en pacientes que acuden a consulta pediátrica en dos instituciones de la Ciudad de Valencia, Estado Carabobo, Venezuela. Acta odontológica venezolana. 2016; 54(2): 11-21. Disponible en https://www. actaodontologica.com/ediciones/2016/2/art-6/

4. Torres-Ramos Gilmer, Blanco-Victorio Daniel José, Chávez-Sevillano, Manuel Gustavo, Apaza-Ramos Sonia, Antezana -Vargas Virginia, Impacto de la caries de la infancia temprana en la calidad de vida relacionada a la salud bucal en niños peruanos menores de 71 meses de edad. Odontol. Sanmarquina 2015; 18(2):87-94. Disponible en https://www.researchgate.net/publication/307144370_Impacto_de_ la_caries_de_la_infancia_temprana_en_la_calidad_de_vida_relacionada_a_la_salud_bucal_en_ninos_ peruanos_menores_de_71_meses_de_edad

5. Zambrano O, Fong L, Rivera L, Calatayud E, Hernández J, Maldonado A, Rojas-Sánchez F, Principe S,Pérez G, Navarro T, Acevedo A. Impacto de la caries de infancia temprana en la calidad de vida del niño zuliano y su familia. ODOUS Científica. 2015; 16(2): 8-17. ISSN: 1315 2823. Disponible en http:// servicio.bc.uc.edu.ve/odontologia/revista/vol16-n2/art01.pdf

6. American Academy of Pediatric Dentistry. Oral Health Policies: Ecc: Classification, Consequences, Preventive Strategies. The reference manual of pediatric dentistry. Manual de Referencia de Odontología Pediátrica. 2019-2020. 71-73. Disponible en https://www.aapd.org/research/oral-health-policies-recommendations/early-childhood-caries-classifications-consequences-and-preventive-strategies/

7. Rodrigues JZS, Passos MR, De Macêdo Neres Silvia, Almeida RS, Pita LS y col. Antimicrobial activity of Lactobacillus fermentum TcUESC01 against Streptococcus mutans UA159. Microb Pathog. 2020. 24; 142: 104063.doi:10.1016/j.micpath.2020.104063. PMID: 32061821. Disponible en https://www.ncbi.nlm.nih. gov/pubmed/32061821

8. Bustillos Torrez W, Bueno Bravo ZS. Inhibición de Streptococcus mutans aislado de cavidad oral de niños sin caries mediante sustancia antagónica producida por Lactobacillus spp. Rev. Odontopediatr. Latinoam.;10(1). Disponible en: https://www.revistaodontopediatria.org/index.php/alop/article/ view/181

9. Bullappa D, Puranik MP, Sowmya KR, Nagarathnamma T. Association of Feeding Methods and Streptococcus mutans Count with Early Childhood Caries: A Cross-sectional Study. Int J Clin Pediatr Dent 2017;10(2):119-125. Disponible en https://www.ncbi.nlm.nih.gov/pubmed/28890609

10. Ramón Jimenez Ruth, Castañeda Deroncelé Mario, Corona Carpio Marcia Hortensia, Estrada Pereira Gladys Aída, Quinzán Luna Ana Maria. Risk factors of dental decay in school children aged 5 to 11. MEDISAN; 2016; 20(5): 604-610. doi: 10.5005/jp-journals-10005-1628. Disponible en https://pesquisa. bvsalud.org/portal/resource/pt/lil-783699

11. Gupta T, Sadana G, Rai H. Effect of Esthetic Defects in Anterior Teeth on the Emotional and Social Wellbeing of Children: A Survey. Int J Clin Pediatr Dent 2019; 12(3): 229-232. Disponible en https://www.ncbi. nlm.nih.gov/pmc/articles/PMC6811947/

12. World Health Organization. Oral Health Programme, Prevention of Noncommunicable Diseases WHO Headquarters. 2019. 1-57 Ending childhood dental caries: WHO implementation manual. ISBN 978-92-4000005-6. Disponible en https://apps.who.int/iris/handle/10665/330643

13. Desafío de las Enfermedades Bucodentales - Una llamada a la acción global. Atlas de Salud Bucodental. $2^{a}$ ed. Ginebra: Federación Dental Internacional (FDI); 2015.1-119. ISBN: 978-2-9700934-9-7. Disponible en http://www.fdiworldental.org/media/84768/book_spreads_oh2_spanish.pdf

14. Arokiaraj Stephen, Ramesh Krishnan, and Paul Chalakkal. The Association between Cariogenic Factors and the Occurrence of Early Childhood Caries in Children from Salem District of India. J Clin Diagn Res. 2017 Jul; 11(7): ZC63-ZC66. doi: 10.7860/JCDR/2017/25574.10217. Disponible en https://www.ncbi.nlm. nih.gov/pmc/articles/PMC5583795/

15. Karibe H, Shimazu K, Okamoto A, Kawakami T, Kato Y, Warita-Naoi S.Prevalence and association of selfreported anxiety, pain, and oral parafunctional habits with temporomandibular disorders in Japanese children and adolescents: a cross-sectional survey. BMC Oral Health. 2015; 15(8). doi: 10.1186/1472-683115-8. Disponible en https://www.ncbi.nlm.nih.gov/pmc/articles/PMC5583795/

16. Lozada DBD, Hernández MN, Guerra GME. Relación entre periodo de amamantamiento y la presencia de hábitos nocivos en niños Venezolanos. Rev Odotopediatr Latinoam. 2015;5(1):22-32.

17. Rondón RG, Zambrano GA, Guerra ME, et al. Relación entre un periodo de lactancia materna exclusiva menor de 6 meses y presencia de hábitos parafuncionales en un grupo de niños y adolescentes venezolanos. Rev Odotopediatr Latinoam. 2018;8(1):16-28.

18. Borrie FR, Bearn DR, Innes NP, Iheozor-Ejiofor Z. Interventions for the cessation of non-nutritive sucking habits in children. Cochrane Database Syst Rev. NCBI 2015; 31(3): CD008694 doi: 10.1002/14651858. CD008694.pub2. Disponible en https://www.ncbi.nlm.nih.gov/pubmed/25825863 
19. Drawanz Hartwig Andréia, Romano Ana Regina, Pappen Fernanda Geraldo, Azevedo Marina Sousa. Fatores maternos relacionados à alta frequência de consumo de sacarose por crianças acompanhadas por um programa de atenção odontológica materno-infantil nos dois primeiros anos de vida. RFO UPF, Passo Fundo, 2018; 23(2):173-179. Disponible en http://seer.upf.br/index.php/rfo/article/view/8305

20. Dos Santos BRA, Carminatti M, Carneiro A, et al. Influencia de los hábitos orales en el perfil miofuncional orofacial de niños de tres a cinco años. Rev Odotopediatr Latinoam. 2020;10(1):13-23

21. Charisma Y. Atkins, BS, Timothy K. Thomas, Dane Lenaker, Gretchen M. Day, Thomas W. Hennessy, Martin I. Meltzer, Cost-effectiveness of preventing dental caries and full mouth dental reconstructions among Alaska Native children in the Yukon-Kuskokwim delta region of Alaska J Public Health Dent. 2016; 76(3): 228-240. doi: 10.1111/jphd.12141. Disponible en https:/www.ncbi.nlm.nih.gov/pmc/articles/ PMC5010502/

22. Utsana, Tonmukayakul y Peter Arrow. Cost-effectiveness analysis of the atraumatic restorative treatmentbased approach to managing early childhood caries. 2017;45 (1) 92-100. https://doi.org/10.1111/cdoe.12265. Disponible en https://onlinelibrary.wiley.com/doi/abs/10.1111/cdoe.12265

23. Gómez A, Bernal T, Posada A, Agudelo A. Caries dental, higiene bucal y necesidades de tratamiento en población de 3 a 5 años de una institución educativa de Medellin y sus factores relacionados. Rev Nac Odontol. 2015; 11 (21): 23-35. Disponible en https://revistas.ucc.edu.co/index.php/od/article/view/933

24. Cubero Santos A, Lorido Cano I, González Huéscar A, Ferrer García MA, Zapata Carrasco MD, Ambel Sánchez JL. Prevalencia de caries dental en escolares de educación infantil de una zona de salud con nivel socioeconómico bajo. Rev Pediatr Aten Primaria. 2019; 21(82): e47-e59. Disponible en http://scielo.isciii.es/ scielo.php?script=sci_arttext\&pid=S1139-76322019000200007\&lng=es

25. Folayan M, Kolawole K, Oziegbe E, Oyedele T, Oshomoji O, Chukwumah N, Onyejaka N. Prevalence, and early childhood caries risk indicators in preschool children in suburban Nigeria. BMC Oral Health. 2015; 15: 72. doi: 10.1186/s12903-015-0058-y. Disponible en https://www.ncbi.nlm.nih.gov/pmc/articles/ PMC4486704/

26. Guerra-Domínguez E, Martínez-Guerra M, Arias-Ortiz Y, Luis-Fonseca R, Martínez-Jiménez A. Impacto de estrategia educativa sobre lactancia materna a futuras madres durante el periodo 2005 al 2016. MULTIMED. 2017; 21(2) 28-43. Disponible en http://www.revmultimed.sld.cu/index.php/mtm/article/ view/487

27. Cuadros-Mendoza, CA, Vichido-Luna, MA, Montijo-Barrios, E, Zárate-Mondragón, F, Cadena-León, JF, Cervantes-Bustamante, R, Toro-Monjáraz, E, \& Ramírez-Mayans, JA. (2017). Actualidades en alimentación complementaria. Acta pediátrica de México, 38(3), 182-201. Disponible en https://dx.doi.org/10.18233/ apm38no3pp182-2011390 https://www.ojs.actapediatrica.org.mx/index.php/APM/article/view/1390/1026

28. Tungare S, Paranjpe AG. Baby Bottle Syndrome. Treasure Island (FL): StatPearls Publishing; 2020. Disponible en https://www.ncbi.nlm.nih.gov/books/NBK535349/

29. Organización Mundial de la Salud 9. a Conferencia Mundial de Promoción de la Salud. Declaración de Shanghai sobre la Promoción de la Salud. Acuerdo de dirigentes mundiales para promover la salud en pro de los Objetivos de Desarrollo Sostenible. 2016. Disponible en http://www9.who.int/healthpromotion/ conferences/9gchp/es/

30. Albino J and Tiwari T. Preventing Childhood Caries: A Review of Recent Behavioral Research. Journal of Dental Research 2016; 95(1) 35-42 DOI: 10.1177/0022034515609034 jdr.sagepub.com. Disponible en https://www.ncbi.nlm.nih.gov/pubmed/26438210

31. Sánchez Ancha, Yolanda; González Mesa, Francisco Javier; Molina Mérida, Olga; Gil García, María. Guía para la elaboración de protocolos. 2011. Rev Biblioteca Las casas 7(1). Disponible en https://issuu.com/ formacionaxarquia/docs/hospital_axarquia_cuadriptico_memoria_11_1_

32. Kredo T, Bernhardsson S, Machingaidze S, Young T, Louw Q, Ochodo E, Grimmer K. Guide to clinical practice guidelines: the current state of play. Int J Qual Health Care. 2016 Feb;28(1): 122-8. Doi: 10.1093/ intqhc/mzv115. PMID: 26796486; PMCID: PMC4767049. Disponible en https://www.ncbi.nlm.nih.gov/ pubmed/26796486

33. Declaración de Helsinki de la AMM - Principios éticos para las investigaciones médicas en seres humanos. 64 $4^{\mathrm{a}}$ Asamblea General, Fortaleza, Brasil. 2013;1-7. Disponible en https://www.wma.net/es/ policies-post/declaracion-de-helsinki-de-la-amm-principios-eticos-para-las-investigaciones-medicas-enseres-humanos/ http://www.redsamid.net/archivos/201606/2013-declaracion-helsinki-brasil.pdf?1

34. Cahuana A, Palma C, González Y, Palacios E. ¿Podemos mejorarla? Matronas Prof. Rev. Salud bucodental materno-infantil. 2016; 17(1):12-19. Disponible en https://www.federacion-matronas.org/wp-content/ uploads/2018/01/articulo-especial-salud-bucodental.pdf 
35. Moscardini Vilela M, Díaz Huamán S, De Rossi M, Nelson-Filho P, De Rossi A. Odontología para bebés: una posibilidad práctica de promoción de salud bucal. Rev. Odontopediatr. Latinoam.;7(2). Disponible en: https://www.revistaodontopediatria.org/index.php/alop/article/view/139

36. Anyosa-Calderón Y, Fernández-Quijandría B, Gámez P, Jiménez-Guillén A, Martínez-Ccahuana L, Pineda-García J, Perona-Miguel de Priego G. Mitos y evidencias en odontología sobre la gestación. Rev Cient Odontol (Lima). 2019; 7 (1): 113-12. Disponible en https://revistas.cientifica.edu.pe/index.php/ odontologica/article/download/494/551/

37. Asmat-Abanto Angel S, Alvarado-Santillán Guillermo H. Creencias Populares sobre La Salud Oral de Embarazadas Atendidas en Dos Hospitales Peruanos. Int. J. Odontostomat. 2019; 13(4): 486-492. Disponible en https://scielo.conicyt.cl/scielo.php?script=sci_arttext\&pid=S0718-381X2019000400486

38. Sotomayor OR, Velazquez SG, Agüero M. Teaching of self-monitoring dental biofilm to pregnant women, in public hospitals of Paraguay. Rev Odotopediatr Latinoam. 2018;8(1):29-40.

39. Cançado de Figueiredo Marcia, López Jordi María del Carmen. La clínica odontológica del bebé integrando un servicio de salud. Arch. Pediatr. Urug. 2008 Ago79(2):150-157.ISSN 0004-0584versión Online ISSN 1688-1249. Disponible en http://www.scielo.edu.uy/scielo.php?script=sci_arttext\&pid=S1688$12492008000200008 \& \operatorname{lng}=\mathrm{es}$.

40. Abal-Perleche DM, Bárces-Cáceres AD, Chávarri-Vargas LJ, Donoso-Delgado LC, Espichán-Cárdenas MC. Lactancia Materna y Riesgo de Caries. Rev Cient. Odontol 2017; 5 (2): 752-59. DOI: 10.21142/25132754-0502-2017-752-759. Disponible en https://revistas.cientifica.edu.pe/index.php/odontologica/article/ view/379

41. Hernández OE, Taboada AO. Prevalencia y algunos factores de riesgo de caries dental en el primer molar permanente en una población escolar de 6 a 12 años de edad Revista ADM. 2017; 74 (3): 141-145

42. Veléz E, Encalada L, Fernandez MJ, Salinas G. Prevalencia de caries según indice CEOD en escolares de 6 años Cuenca- Ecuador. KIRU. 2019; 16(1): 27 - 31. doi.org/10.24265/kiru. Disponible en https://www. usmp.edu.pe/odonto/servicio/2018/1473-4919-1-PB.pdf

43. Ramírez-Puerta Blanca Susana, Escobar-Paucar Gloria, Franco-Cortés Ángela María, Ochoa-Acosta Emilia María, Otálvaro-Castro Gabriel Jaime, Agudelo-Suárez Andrés Alonso. Caries dental en niños de 0-5 años del municipio de Andes, Colombia. Evaluación mediante el sistema internacional de detección y valoración de caries - ICDAS. Rev. Fac. Nac. Salud Pública. 2017; 35(1): 91-98. Disponible en http:// www.scielo.org.co/scielo.php?script=sci_arttext\&pid=S0120-386X2017000100091\&lng=en. http://dx.doi. org/10.17533/udea.rfnsp.v35n1a10.

44. Jacquett Toledo Ninfa Lucia, Samudio Margarita. Prevalencia de caries en dentición temporal en niños de 1 a 5 años de acuerdo a los criterios ICDAS en el puesto de salud San Miguel de San Lorenzo, Paraguay. Pediatr. 2015; 42(3): 216-224. Disponible en http://dx.doi.org/10.18004/ped.2015.diciembre.216-224.

45. De la Cruz Idalmis, Hernández Alejandrez Ivet, Vidal Borras Emilio, Páez Domínguez. Propuesta de programa educativo para el manejo de la atención estomatológica en mujeres embarazadas. Rev Cubana Salud Pública. 2018; 44(4): 33-46. Disponible en https:/www.scielosp.org/article/rcsp/2018.v44n4/33-46/

46. Bandeira MVR, Belarmino AC, Anjos SJSB, Silva MRF, Ferreira Junior AR. Colaboración interprofesional para el seguimiento odontológico prenatal en atención primaria de la salud. Salud Colectiva. 2019; 15:2224.1-13 doi: 10.18294/sc.2019.2224 Disponible en https://www.scielosp.org/article/scol/2019.v15/ e2224/

47. Moimaz SA, Rocha NB, Garbin AJ, Garbin CA, Saliba. Influence of oral health on quality of life in pregnant women. Acta Odontol Latinoam. 2016; 29(2): 186-193. Disponible en. https://www.ncbi.nlm.nih. gov/pubmed/27731489/

48. Albino J. and T. Tiwari T. Preventing Childhood Caries: A Review of Recent Behavioral Research Journal of Dental Research. Critical Reviews in Oral Biology \& Medicine. 2016; 95(1): 35-42 DOI: 10.1177/0022034515609034. Disponible en https://www.ncbi.nlm.nih.gov/pubmed/26438210

49. Xiao J, Alkhers N, Kopycka-Kedzierawski DT, et al. Prenatal Oral Health Care and Early Childhood Caries Prevention: A Systematic Review and Meta-Analysis. Caries Res. 2019; 53(4): 411-421. doi:10.1159/000495187. Disponible en https://www.ncbi.nlm.nih.gov/pmc/articles/PMC6554051/

50. Shashikiran N, Reddy VVS, Raju PK. Effect of antiasthmatic medication on dental disease: Dental caries and periodontal disease. J Indian Soc Pedod Prev Dent. 2007;25(2):65-8.

51. Ramos J, Ramírez E, Vázquez EM, Vázquez F. Repercusiones en la salud bucodental asociadas con el asma en niños de 6 a 12 años de edad. Rev Alerg Mex. 2017;64(3):270-76.

52. Jain M, Mathur A, Sawla L, Nihlani T, Gupta S, Prabu D, et al. Prevalence of dental erosion among asthmatic patients in India. Rev clín pesq odontol. 2009;5(3):247-54. 
53. Hermida L, Restrepo C. Bruxismo del sueño y sídrome de apnea obstructiva del sueño en niños. Revisión narrativa. Revista de Odontopediatría Latinoamericana. 2016;6(2):99-107.

54. American Academy of Sleep Medicine. The International Classification of sleep disorders: Diagnostic and coding manual. 2nd ed. American Academy of Sleep Medicine; 2005.

55. Bolaños E, Gonzales E, Del Castillo E. El bruxismo infantil. Odontol Pediátrica. 2002;10(3):135-41.

56. Bortoletto C, Marques A, Ferrari RA, Fernandes KP, Bussadori S, Motta L. Association between respiratory problems and dental caries in children with bruxism. Indian J Dent Res. 2014;25(1):9.

Recibido: $29 / 04 / 20$

Aceptado: 02/05/21

Correspondencia: María Sierraalta Quiñones, correo: masierraaltaq@gmail.com 